\section{Stereotactic and Functional \\ Neurosurgery}

Stereotact Funct Neurosurg 2011;89:56-61

DOI: $\underline{10.1159 / 000322277}$
Received: August 26, 2010

Accepted after revision: October 24, 2010

Published online: January 19, 2011

\title{
Citation Measures in Stereotactic Radiosurgery: Publication across a Discipline
}

\author{
Douglas Kondziolka ${ }^{a}, b$ \\ Departments of a Neurological Surgery and ${ }^{b}$ Radiation Oncology, University of Pittsburgh, \\ Center for Image-Guided Neurosurgery, Pittsburgh, Pa., USA
}

\section{Key Words}

Stereotactic radiosurgery $\cdot$ Citations $\cdot$ Publications $\cdot$

Research

\begin{abstract}
Objective: It is possible to judge the impact of scientific research by the number of citations a publication has received. We identified the most cited works in the field of stereotactic radiosurgery to study the evolution of this field from the perspective of publication. Methods: A Web of Science search was performed for articles that included the word 'radiosurgery' in the title. We studied the reports with $>100$ citations. Results: A total of 5,532 published works were available for study between 1951 and 2010. Eighty-five articles had $\geq 100$ citations, and these were published in 19 separate journals. The majority were published in the International Journal of Radiation Oncology, Biology and Physics, the Journal of Neurosurgery and Neurosurgery. The most common topics included brain metastasis management $(n=20)$, arteriovenous malformations ( $n=17)$, vestibular schwannomas $(n=9)$, technologies $(n=9)$, meningiomas $(n=8)$ and dose response/ radiobiology $(n=6)$. Fifty-seven percent of the articles were published in the last 10 years. Conclusions: The first radiosurgery report by Leksell (1951) initiated the field. The 1980s were a period of new technology development followed in
\end{abstract}

the 1990s by introductory articles on specific indications that consisted mainly of retrospective case series. More sophisticated higher level evidence reports were published in the last decade. The most significant works in radiosurgery include initial technology descriptions, multicenter studies with large numbers of patients, randomized clinical trials and reports that provide dose prescription guidelines.

Copyright $\odot 2011$ S. Karger AG, Basel

\section{Introduction}

Stereotactic radiosurgery has a history spanning 60 years but with increasing use and rapid growth of indications over the last 30. An analysis of published reports over these decades provides insight into what kinds of research have had the most impact and have fostered the scientific direction of the field. The hypothesis was that through an analysis of publication trends and citation evaluations, one could gain a better understanding of the evolution of and valuation of the discipline. This study describes the most highly cited articles in the field of stereotactic radiosurgery. Other similar reports related to Parkinson's disease and neurosurgery in general provided the impetus for this study [1-3].

\section{KARGER}

Fax +4161306 1234 E-Mail karger@karger.ch www.karger.com
(C) 2011 S. Karger AG, Basel

1011-6125/11/0891-0056\$38.00/0

Accessible online at:

www.karger.com/sfn
Douglas Kondziolka, MD

University of Pittsburgh, Suite B-400, UPMC Presbyterian

200 Lothrop Street, Pittsburgh, PA 15213 (USA)

Tel. +1 412647 6782, Fax +1 4126476483

E-Mail kondziolkads@upmc.edu 


\section{Methods}

A search was performed on the ISI Web of Science Bibliometric Database for articles that included the key word 'radiosurgery' in the title. This search was performed on June 22, 2010, and included all the articles tracked by that database. The search provided 5,532 articles published between 1951 and 2010. The vast majority of these reports were scientific articles (49\%) but also included documents related to meetings (35\%), abstracts (20\%), editorials (10\%), review articles (3.7\%), letters (2.9\%), books (2.3\%), case reports $(0.94 \%)$ and clinical trials $(0.38 \%)$. Analysis was restricted to those having received $\geq 100$ citations. The concept of a 'citation classic' has been noted by others [4], typically associated with $>400$ citations. However, this applied to only 1 article in the field. For this reason, the analysis was conducted on articles with $>100$ citations. In this report, numbers in parentheses indicate the rank of the article in order of number of citations (table 1).

\section{Results}

One article met the criteria for a 'citation classic' with $>400$ citations. This was the original article by Lars Leksell, 'The stereotaxic method and radiosurgery of the brain' (Acta Chir Scand 1951;102:316-319). This report had 614 citations. This report from 1951 coined the term 'radiosurgery' and is the first article listed. Interestingly, the second article published with the word 'radiosurgery' in the title was by Gros et al. in 1954, entitled 'Radiosurgery of ovarian cancer,' published in J Radiol Electrol Arch Elect Medicale. There are only 6 articles with $>300$ citations, 13 with $>200$ and 85 with $\geq 100$. The 6 with $>300$ citations are on the topic of brain metastases (table 1 listings $2,5,6)$, whereas the others are on arteriovenous malformations (table 1 listings 3, 4). Two of the brain metastasis articles with 371 and 311 citations were 1994 and 1995 retrospective series published by the University of Pittsburgh and Harvard University Joint Center, respectively. The 2004 Radiation Therapy Oncology Group randomized trial published in Lancet has 310 citations and, due to its more recent publication, might be considered to be the most important article on brain metastasis radiosurgery.

\section{Clinical Topics}

\section{Technology Assessments}

Nine reports describe radiosurgical systems: modified linear accelerator radiosurgery $(\mathrm{n}=4)$, CyberKnife $(\mathrm{n}=$ $2)$, Gamma Knife $(n=1)$ and other $(n=2)$. Most of these works are from the 1980s and 1990s.

\section{Clinical Indications}

Sixty-six of the 85 articles dealt with clinical indications such as metastases $(\mathrm{n}=20)$, arteriovenous malformations ( $\mathrm{n}=17)$, acoustic neuromas $(\mathrm{n}=9)$, meningiomas $(n=8)$, trigeminal neuralgia $(n=5)$, gliomas $(\mathrm{n}=2)$, spinal radiosurgery $(\mathrm{n}=2)$, pain management $(n=1)$, cavernous malformations $(n=1)$ and lung cancer $(\mathrm{n}=1)$.

\section{Physics and Radiobiology}

Six reports studied the dose-response relationship for brain and cranial nerve tolerance for the radiobiology of a normal brain or brain-tumor responses. Four articles describe physics testing related to specific radiosurgical devices or methods for quality assurance and maintenance of the devices.

\section{Journals}

The most frequent journals used to publish radiosurgical articles included the major journals of the neurosurgery or radiation oncology communities. The International Journal of Radiation Oncology, Biology and Physics had 23 of the top 85 articles. The Journal of Neurosurgery similarly had 23 articles, and Neurosurgery had 18. Important works related to brain metastasis management were published in the Journal of Clinical Oncology $(\mathrm{n}=4)$ and Cancer $(\mathrm{n}=2)$. Initial reports by Lars Leksell on the radiosurgical method were published in Acta Chirurgica Scandinavica. Other journals with 1 report each covered a spectrum of different topics. These included the New England Journal of Medicine, Lancet, Journal of the National Cancer Institute, Journal of Neurology, Neurosurgery, and Psychiatry, JAMA, Surgical Neurology, Stereotactic and Functional Neurosurgery, The British Journal of Radiology, Radiotherapy Oncology, Neurology, and also Thoracic Surgery, Acta Neurochirurgica, and Physics in Medicine and Biology.

Articles in general interest high-impact journals, such as the New England Journal of Medicine and Lancet, included a long-term assessment of acoustic neuroma radiosurgery (table 1 listing 9) and the brain metastasis randomized trial from the Radiation Therapy Oncology Group (table 1 listing 5). 


\section{Years of Publication}

After the first article had been published in 1951, the first 3 decades of the radiosurgical era were associated with only a small number of reports. Only 2 papers were published in the years 1959, 1963, 1971, 1972, 1973 and 1984. Three each were published in 1967 and 1978, and 4 were published in 1983. At this time only a handful of institutions performed radiosurgery, typically centers that had developed their own technology. The annual number of reports doubled from 7 to 16 in 1987. Rapid publication growth in the field then began in $1989(\mathrm{n}=41), 1990(\mathrm{n}=$ 62), $1991(\mathrm{n}=89), 1992(\mathrm{n}=114), 1993(\mathrm{n}=125)$ and 1994 $(\mathrm{n}=155)$. By 1996, 279 articles were published and by 2000 , 330. In the last decade alone, 3,132 articles were published, representing $57 \%$ of the total. Thus, the mean number of articles published annually in the 1980 s was 9.6 , during the 1990 s it was 178 , and during the 2000s it was 313 .

\section{Institutions}

Of the 85 reports with $>100$ citations, 29 were published from the University of Pittsburgh. Other centers in the USA included the Harvard Joint Center $(\mathrm{n}=12)$, University of Florida $(n=4)$, Stanford University $(n=5)$ and the University of California at San Francisco $(n=4)$. Authors from the Karolinska Institute in Stockholm published 5 of these articles. Centers with 2 articles included the University of Wisconsin, Thomas Jefferson University, Vicenza and Henry Ford Hospital (Detroit). The University of Virginia, Mayo Clinic, Montreal Neurological Institute, Northwest Hospital (Seattle), University of California at Berkeley, Tokyo Women's University, University of Munich, Royal Adelaide Hospital, Columbia University, MD Anderson Cancer Center, Hôpital Lariboisière (Paris), Hokkaido University, the University of Heidelberg, and centers in Zurich and Buenos Aires published 1 article each.

\section{Discussion}

Stereotactic radiosurgery is a field that impacts on a broad array of topics in neurosurgery, radiation oncology and medical physics. Radiosurgery has had an impact in the management of disorders related to vascular malformations, benign and malignant brain tumors, movement disorders, pain management and psychiatric disease. As a technology-driven field, physics reports and radiobio- logical studies serve as the foundation for clinical use. Although conceived and initially developed in the 1950s and 1960s, radiosurgery was a field ahead of its time. Not until high-resolution intraparenchymal imaging with magnetic resonant techniques was available, did radiosurgery truly impact upon high numbers of patients followed by installations at centers in many countries. Indeed radiosurgical practice was limited initially to highvolume academic centers and now is present in many community-based hospitals.

\section{The Most Cited Reports}

Our analysis of reports with $>100$ citations noted that only 1 met the criteria of a citation classic with $>400$, that being the report that described the radiosurgical method. Five other articles with $>300$ citations include 3 on the topic of brain metastases and 2 on arteriovenous malformations. The balance between contributions from neurosurgery and radiation oncology is reflected by a similar 23 reports in both the International Journal of Radiation Oncology, Biology and Physics and the Journal of Neurosurgery. There have been an additional 18 articles that were published in Neurosurgery and 6 more in oncology journals. There does remain a significant balance between reports that were submitted and published in these different disciplines.

\section{The Evolution of Radiosurgery Publications}

As noted, radiosurgery did not gain much attraction until the late 1980s with general clinical use supported by high-resolution imaging being performed. A significant jump between the mean number of annual articles in the 1980s (9.6) and the 1990s (178) can be explained by several factors. First, the use of imaging allowed a wider number of indications to be evaluated and published (including brain metastasis, meningiomas, pituitary tumors and functional indications); second, the availability of commercially manufactured radiosurgical systems rather than home-grown devices meant that more institutions could purchase radiosurgical systems. Prior to the late 1980s, the manufacturer of the Leksell Gamma Knife had only limited capability to develop their radiosurgical system, and available modified linear accelerator platforms were all built at individual institutions. It was not until the 1990s that commercially available stereotactic LINAC radiosurgical devices were more widely available.

Prior to 1995, formal training in radiosurgical techniques usually consisted of a fellowship which was not widely available to practicing physicians. Dedicated training courses allowed surgeons, radiation oncologists 
and medical physicists to learn the nuances of their radiosurgical device and meet institutional requirements before beginning patient care.

\section{Study Limitations}

It is difficult for more recent articles, despite their more significant contribution to science, to amass a critical number of citations and be included in this list. However, the 2004 Radiation Therapy Oncology Group randomized trial in Lancet with 310 citations helped to substantiate the role of radiosurgery in brain metastasis management and despite the shorter time to collect citations, it already has a place in the top 5. The lack of other more recent articles with a large number of citations may indicate that there have been no reports with similar significant impact during this most recent decade. It will be interesting to track the citations of the recently published guidelines for brain metastasis management in the Journal of Neuro-Oncology (2009).

A topic search to identify articles and citations can be conducted in numerous ways. In this report a search was conducted using the term 'radiosurgery'. To test the reliability of this choice, a separate search was conducted using 'gamma knife surgery', which yielded 433 articles, only 2 with $>100$ citations. One was No. 105 in table 1, and only 1 separate report with 120 citations (Karlsson et al.: Prediction of obliteration after gamma knife surgery for cerebral arteriovenous malformations. Neurosurgery 1997;40: 425-430) was found. An additional search on the term 'gamma knife' yielded 2,125 articles, 9 with $>100$ citations, of which 7 were identified in the original search. The 2 missed reports include the Karlsson article noted above and a report on vascular malformation histopathology.

Finally, it is worthwhile to comment on the wide variety of journals that contain the top 85 articles with $>100$ citations. As noted, these include neurosurgical, radiation oncology, neurology, physics, oncology and journals of general interest. Some authors have called for a specific journal on the topic of stereotactic radiosurgery. Over a decade ago, the Journal of Radiosurgery was created but failed due to lack of submissions and other factors. Another publication, Radiosurgery, is the official journal of the International Stereotactic Radiosurgery Society and is published every 2 years with the top peer-reviewed science submitted to the meeting of the International Stereotactic Radiosurgery Society. It is not published often enough for most authors to submit their most important works. The existing array of journals appears to be adequate for radiosurgery articles, each providing their own unique readership but with broad international access.
Table 1. Radiosurgery articles with $>100$ citations, ranked in order of citations received

\section{Cita- Reference}

tions

614 Leksell, L. (1951). The Stereotaxic method and radiosurgery of the brain. Acta Chirurgica Scandinavica, 102(4), 316-319.

372 Flickinger, J.C., Kondziolka, D., Lunsford, L.D., Coffey, R.J., Goodman, M.L., Shaw, E.G., et al. (1994). A multiinstitutional experience with stereotaxic radiosurgery for solitary brain metastasis. International Journal of Radiation Oncology Biology Physics, 28(4), 797-802.

354 Lunsford, L.D., Kondziolka, D., Flickinger, J.C., Bissonette, D.J., Jungreis, C.A., Maitz, A.H., et al. (1991). Stereotaxic radiosurgery for arteriovenous-malformations of the brain. Journal of Neurosurgery, 75(4), 512-524.

322 Steiner, L., Lindquist, C., Adler, J.R., Torner, J.C., Alves, W., Steiner, M. (1992). Clinical outcome of radiosurgery for cerebral arteriovenous-malformations. Journal of Neurosurgery, 77(1), 1-8.

316 Andrews, D.W., Scott, C.B., Sperduto, P.W., Flanders, A.E., Gaspar, L.E., Schell, M.C., et al. (2004). Whole brain radiation therapy with or without stereotactic radiosurgery boost for patients with one to three brain metastases: phase III results of the RTOG 9508 randomised trial. Lancet, 363(9422), 1665-1672.

312 Alexander, E., Moriarty, T.M., Davis, R.B., Wen, P.Y., Fine, H.A., Black, P.M., et al. (1995). Stereotaxic radiosurgery for the definitive, noninvasive treatment of brain metastases. Journal of the National Cancer Institute, 87(1), 34-40.

292 Lutz, W., Winston, K.R., Maleki, N. (1988). A system for stereotactic radiosurgery with a linear-accelerator. International Journal of $R a$ diation Oncology Biology Physics, 14(2), 373-381.

278 Kondziolka, D., Patel, A., Lunsford, L.D., Kassam, A., Flickinger, J.C. (1999). Stereotactic radiosurgery plus whole brain radiotherapy versus radiotherapy alone for patients with multiple brain metastases. International Journal of Radiation Oncology Biology Physics, 45(2), 427-434.

277 Kondziolka, D., Lunsford, L.D., McLaughlin, M.R., Flickinger, J.C. (1998). Long-term outcomes after radiosurgery for acoustic neuromas. New England Journal of Medicine, 339(20), 1426-1433.

268 Auchter, R.M., Lamond, J.P., Alexander, E., Buatti, J.M., Chappell, R., Friedman, W.A., et al. (1996). A multiinstitutional outcome and prognostic factor analysis of radiosurgery for resectable single brain metastasis. International Journal of Radiation Oncology Biology Physics, 35(1), 27-35.

217 Colombo, F., Pozza, F., Chierego, G., Casentini, L., Deluca, G., Francescon, P., et al. (1994). Linear-accelerator radiosurgery of cerebral arteriovenous-malformations - an update. Neurosurgery, 34(1), 1421.

212 Betti, O.O., Munari, C., Rosler, R. (1989). Stereotactic radiosurgery with the linear-accelerator - treatment of arteriovenous-malformations. Neurosurgery, 24(3), 311-321.

203 Leksell, L. (1983). Stereotactic radiosurgery. Journal of Neurology Neurosurgery and Psychiatry, 46(9), 797-803.

191 Kondziolka, D., Lunsford, L.D., Flickinger, J.C., Young, R.F., Vermeulen, S., Duma, C.M., et al. (1996). Stereotactic radiosurgery for trigeminal neuralgia: a multiinstitutional study using the gamma unit. Journal of Neurosurgery, 84(6), 940-945.

188 Sneed, P.K., Lamborn, K.R., Forstner, J.M., McDermot, M.W., Chang, S., Park, E., et al. (1999). Radiosurgery for brain metastases: is whole brain radiotherapy necessary? International Journal of $R a$ diation Oncology Biology Physics, 43(3), 549-558.

185 Leber, K.A., Bergloff, J., Pendl, G. (1998). Dose-response tolerance of the visual pathways and cranial nerves of the cavernous sinus to stereotactic radiosurgery. Journal of Neurosurgery, 88(1), 43-50.

183 Duma, C.M., Lunsford, L.D., Kondziolka, D., Harsh, G.R., Flickinger, J.C., Larson, D.A., et al. (1993). Stereotaxic radiosurgery of cavernous sinus meningiomas as an addition or alternative to microsurgery. Neurosurgery, 32(5), 699-705. 
Cita- Reference

tions

182 Friedman, W.A., Bova, F.J., Mendenhall, W.M. (1995). Linear-accelerator radiosurgery for arteriovenous-malformations - the relationship of size to outcome. Journal of Neurosurgery, 82(2), 180-189.

182 Loeffler, J.S., Kooy, H.M., Wen, P.Y., Fine, H.A., Cheng, C.W., Mannarino, E.G., et al. (1990). The treatment of recurrent brain metastases with stereotactic radiosurgery. Journal of Clinical Oncology, 8(4), 576-582.

177 Pollock, B.E., Lunsford, L.D., Kondziolka, D., Flickinger, J.C., Bissonette, D.J., Kelsey, S.F., et al. (1995). Outcome analysis of acoustic neuroma management - a comparison of microsurgery and stereotaxic radiosurgery. Neurosurgery, 36(1), 215-224.

177 Mehta, M.P., Rozental, J.M., Levin, A.B., Mackie, T.R., Kubsad, S.S., Gehring, M.A., et al. (1992). Defining the role of radiosurgery in the management of brain metastases. International Journal of Radiation Oncology Biology Physics, 24(4), 619-625.

176 Kondziolka, D., Lunsford, L.D., Coffey, R.J., Flickinger, J.C. (1991). Stereotaxic radiosurgery of meningiomas. Journal of Neurosurgery, 74(4), 552-559.

176 Flickinger, J.C. (1989). An Integrated logistic formula for prediction of complications from radiosurgery. International Journal of Radiation Oncology Biology Physics, 17(4), 879-885.

175 Podgorsak, E.B., Olivier, A., Pla, M., Lefebvre, P.Y., Hazel, J. (1988). Dynamic stereotactic radiosurgery. International Journal of Radiation Oncology Biology Physics, 14(1), 115-126.

173 Sneed, P.K., Suh, J.H., Goetsch, S.J., Sanghavi, S.N., Chappell, R., Buatti, J.M., et al. (2002). A multi-institutional review of radiosurgery alone vs. radiosurgery with whole brain radiotherapy as the initial management of brain metastases. International Journal of Radiation Oncology Biology Physics, 53(3), 519-526.

171 Tishler, R.B., Loeffler, J.S., Lunsford, L.D., Duma, C., Alexander, E., Kooy, H.M., et al. (1993). Tolerance of cranial nerves of the cavernous sinus to radiosurgery. International Journal of Radiation Oncology Biology Physics, 27(2), 215-221.

170 Loeffler, J.S., Alexander, E., Shea, W.M., Wen, P.Y., Fine, H.A., Kooy, H.M., et al. (1992). Radiosurgery as part of the initial management of patients with malignant gliomas. Journal of Clinical Oncology, 10(9), 1379-1385.

168 Adler, J.R., Murphy, M.J., Chang, S.D., Hancock, S.L. (1999). Imageguided robotic radiosurgery. Neurosurgery, 44(6), 1299-1306.

167 Flickinger, J.C., Kondziolka, D., Niranjan, A., Lunsford, L.D. (2001) Results of acoustic neuroma radiosurgery: an analysis of 5 years' experience using current methods. Journal of Neurosurgery, 94(1), 1-6.

162 Winston, K.R., Lutz, W. (1988). Linear-accelerator as a neurosurgical tool for stereotactic radiosurgery. Neurosurgery, 22(3), 454-464.

161 Pirzkall, A., Debus, J., Lohr, F., Fuss, M., Rhein, B., Engenhart-Cabillic, R., et al. (1998). Radiosurgery alone or in combination with whole-brain radiotherapy for brain metastases. Journal of Clinical Oncology, 16(11), 3563-3569.

161 Gobin, Y.P., Laurent, A., Merienne, L., Schlienger, M., Aymard, A., Houdart, E., et al. (1996). Treatment of brain arteriovenous malformations by embolization and radiosurgery. Journal of Neurosurgery, 85(1), 19-28.

153 Aoyama, H., Shirato, H., Tago, M., Nakagawa, K., Toyoda, T., Hatano, K., et al. (2006). Stereotactic radiosurgery plus whole-brain radiation therapy vs stereotactic radiosurgery alone for treatment of brain metastases - a randomized controlled trial. JAMA -Journal of the American Medical Association, 295(21), 2483-2491.

149 Shaw, E., Kline, R., Gillin, M., Souhami, L., Hirschfeld, A., Dinapoli, R., et al. (1993). Radiation-Therapy Oncology Group - Radiosurgery Quality Assurance Guidelines. International Journal of Radiation Oncology Biology Physics, 27(5), 1231-1239.

143 Lunsford, L.D., Flickinger, J., Lindner, G., Maitz, A. (1989). Stereotactic radiosurgery of the brain using the 1st United-States 201-cobalt-60 source gamma-knife. Neurosurgery, 24(2), 151-159.
Cita- Reference

tions

141 Colombo, F., Benedetti, A., Pozza, F., Marchetti, C., Chierego, G. (1989). Linear-accelerator radiosurgery of cerebral arteriovenousmalformations. Neurosurgery, 24(6), 833-840.

139 Nedzi, L.A., Kooy, H., Alexander, E., Gelman, R.S., Loeffler, J.S. (1991). Variables Associated with the development of complications from radiosurgery of intracranial tumors. International Journal of Radiation Oncology Biology Physics, 21(3), 591-599.

139 Wu, A., Lindner, G., Maitz, A.H., Kalend, A.M., Lunsford, L.D., Flickinger, J.C., et al. (1990). Physics of gamma-knife approach on convergent beams in stereotaxic radiosurgery. International Journal of Radiation Oncology Biology Physics, 18(4), 941-949.

139 Noren, G., Arndt, J., Hindmarsh, T. (1983). Stereotactic radiosurgery in cases of acoustic neurinoma - further experiences. Neurosurgery, 13(1), 12-22.

137 Hall, E.J., Brenner, D.J. (1993). The radiobiology of radiosurgery rationale for different treatment regimes for AVMS and malignancies. International Journal of Radiation Oncology Biology Physics, 25(2), 381-385.

136 Pollock, B.E., Flickinger, J.C., Lunsford, L.D., Bissonette, D.J., Kondziolka, D. (1996). Hemorrhage risk after stereotactic radiosurgery of cerebral arteriovenous malformations. Neurosurgery, 38(4), 652-659.

135 Friedman, W.A., Bova, F.J. (1992). Linear-accelerator radiosurgery for arteriovenous-malformations. Journal of Neurosurgery, 77(6), 832-841.

133 Landolt, A.M., Haller, D., Lomax, N., Scheib, S., Schubiger, O., Siegfried, J., et al. (1998). Stereotactic radiosurgery for recurrent surgically treated acromegaly: comparison with fractionated radiotherapy. Journal of Neurosurgery, 88(6), 1002-1008.

133 Bindal, A.K., Bindal, R.K., Hess, K.R., Shiu, A., Hassenbusch, S.J., Shi, W.M., et al. (1996). Surgery versus radiosurgery in the treatment of brain metastasis. Journal of Neurosurgery, 84(5), 748-754.

132 Adler, J.R., Chang, S.D., Murphy, M.J., Doty, J., Geis, P., Hancock, S.L. (1997). The cyberknife: a frameless robotic system for radiosurgery. Stereotactic and Functional Neurosurgery, 69(1-4), 124-128.

132 Fuller, B.G., Kaplan, I.D., Adler, J., Cox, R.S., Bagshaw, M.A. (1992). Stereotaxic radiosurgery for brain metastases - the importance of adjuant whole brain irradiation. International Journal of Radiation Oncology Biology Physics, 23(2), 413-418.

132 Friedman, W.A., Bova, F.J. (1989). The University-of-Florida Radiosurgery System. Surgical Neurology, 32(5), 334-342.

131 Shrieve, D.C., Alexander, E., Wen, P.Y., Fine, H.A., Kooy, H.M., Black, P.M.L., et al. (1995). Comparison of stereotaxic radiosurgery and brachytherapy in the treatment of recurrent glioblastoma-multiforme. Neurosurgery, 36(2), 275-282.

131 Leksell, L. (1968). Cerebral radiosurgery. I. Gammathalamotomy in 2 cases of intractable pain. Acta Chirurgica Scandinavica, 134(8), 585-595.

130 Larson, D.A., Flickinger, J.C., Loeffler, J.S. (1993). The Radiobiology of radiosurgery. International Journal of Radiation Oncology Biology Physics, 25(3), 557-561.

128 Ryu, S., Yin, F.F., Rock, J., Zhu, J.E., Chu, A., Kagan, E., et al. (2003). Image-guided and intensity-modulated radiosurgery for patients with spinal metastasis. Cancer, 97(8), 2013-2018.

126 Fabrikant, J.I., Lyman, J.T., Hosobuchi, Y. (1984). Stereotactic heavyion bragg peak radiosurgery for intra-cranial vascular disorders method for treatment of deep arteriovenous-malformations. British Journal of Radiology, 57(678), 479-490.

124 Flickinger, J.C., Lunsford, L.D., Linskey, M.E., Duma, C.M., Kondziolka, D. (1993). Gamma-knife radiosurgery for acoustic tumors multivariate-analysis of 4-year results. Radiotherapy and Oncology, 27(2), 91-98.

123 Kondziolka, D., Levy, E.I., Niranjan, A., Flickinger, J.C., Lunsford, L.D. (1999). Long-term outcomes after meningioma radiosurgery: physician and patient perspectives. Journal of Neurosurgery, 91(1), 44-50. 
Cita- Reference

tions

121 Maesawa, S., Salame, C., Flickinger, J.C., Pirris, S., Kondziolka, D., Lunsford, L.D. (2001). Clinical outcomes after stereotactic radiosurgery for idiopathic trigeminal neuralgia. Journal of Neurosurgery, 94(1), 14-20.

121 Lunsford, L.D. (1994). Contemporary management of meningiomas - radiation-therapy as an adjuvant and radiosurgery as an alternative to surgical removal. Journal of Neurosurgery, 80(2), 187-190.

120 Flickinger, J.C., Kondziolka, D., Pollock, B.E., Lunsford, L.D. (1996). Evolution in technique for vestibular schwannoma radiosurgery and effect on outcome. International Journal of Radiation Oncology Biology Physics, 36(2), 275-280.

120 Flickinger, J.C., Pollock, B.E., Kondziolka, D., Lunsford, L.D. (1996). A dose-response analysis of arteriovenous malformation obliteration after radiosurgery. International Journal of Radiation Oncology Biology Physics, 36(4), 873-879.

119 Morita, A., Coffey, R.J., Foote, R.L., Schiff, D., Gorman, D. (1999) Risk of injury to cranial nerves after gamma knife radiosurgery for skull base meningiomas: experience in 88 patients. Journal of Neurosurgery, 90(1), 42-49.

118 Friedman, W.A., Blatt, D.L., Bova, F.J., Buatti, J.M., Mendenhall, W.M., Kubilis, P.S. (1996). The risk of hemorrhage after radiosurgery for arteriovenous malformations. Journal of Neurosurgery, 84(6), 912-919.

117 Pollock, B.E., Phuong, L.K., Gorman, D.A., Foote, R.L., Stafford, S.L. (2002). Stereotactic radiosurgery for idiopathic trigeminal neuralgia. Journal of Neurosurgery, 97(2), 347-353.

116 Lee, J.Y.K., Niranjan, A., McInerney, J., Kondziolka, D., Flickinger, J.C., Lunsford, L.D. (2002). Stereotactic radiosurgery providing longterm tumor control of cavernous sinus meningiomas. Journal of Neurosurgery, 97(1), 65-72.

116 Pollock, B.E., Lunsford, L.D., Kondziolka, D., Maitz, A., Flickinger, J.C. (1994). Patient outcomes after stereotaxic radiosurgery for operable arteriovenous-malformations. Neurosurgery, 35(1), 1-7.

115 Whyte, R.I., Crownover, R., Murphy, M.J., Martin, D.P., Rice, T.W., DeCamp, M.M., et al. (2003). Stereotactic radiosurgery for lung tumors: preliminary report of a phase I trial. Annals of Thoracic Surgery, 75(4), 1097-1101.

115 Mori, Y., Kondziolka, D., Flickinger, J.C., Kirkwood, J.M., Agarwala S., Lunsford, L.D. (1998). Stereotactic radiosurgery for cerebral metastatic melanoma: factors affecting local disease control and survival. International Journal of Radiation Oncology Biology Physics, 42(3), 581-589.

114 Yamamoto, M., Jimbo, M., Hara, M., Saito, I., Mori, K. (1996). Gamma knife radiosurgery for arteriovenous malformations: long-term follow-up results focusing on complications occurring more than 5 years after irradiation. Neurosurgery, 38(5), 906-914

114 Kondziolka, D., Lunsford, L.D., Flickinger, J.C., Kestle, J.R.W. (1995) Reduction of hemorrhage risk after stereotaxic radiosurgery for cavernous malformations. Journal of Neurosurgery, 83(5), 825-831.

112 Shiau, C.Y., Sneed, P.K., Shu, H.K.G., Lamborn, K.R., McDermott, M.W., Chang, S., et al. (1997). Radiosurgery for brain metastases: relationship of dose and pattern of enhancement to local control. International Journal of Radiation Oncology Biology Physics, 37(2), 375383.

111 Ryu, S.I., Chang, S.D., Kim, D.H., Murphy, M.J., Le, Q.T., Martin, D.P., et al. (2001). Image-guided hypo-fractionated stereotactic radiosurgery to spinal lesions. Neurosurgery, 49(4), 838-846.

111 Somaza, S., Kondziolka, D., Lunsford, L.D., Kirkwood, J.M., Flickinger, J.C. (1993). Stereotaxic radiosurgery for cerebral metastatic melanoma. Journal of Neurosurgery, 79(5), 661-666.

110 Linskey, M.E., Flickinger, J.C., Lunsford, L.D. (1993). Cranial nerve length predicts the risk of delayed facial and trigeminal neuropathies after acoustic tumor stereotaxic radiosurgery. International Journal of Radiation Oncology Biology Physics, 25(2), 227-233.
Cita- Reference

tions

108 Pollock, B.E., Kondziolka, D., Lunsford, L.D., Bissonette, D., Flickinger, J.C. (1996). Repeat stereotactic radiosurgery of arteriovenous malformations: factors associated with incomplete obliteration. $\mathrm{Neu}$ rosurgery, 38(2), 318-323.

107 Subach, B.R., Lunsford, L.D., Kondziolka, D., Maitz, A.H., Flickinger, J.C. (1998). Management of petroclival meningiomas by stereotactic radiosurgery. Neurosurgery, 42(3), 437-443.

106 Pollock, B.E., Flickinger, J.C., Lunsford, L.D., Maitz, A., Kondziolka, D. (1998). Factors associated with successful arteriovenous malformation radiosurgery. Neurosurgery, 42(6), 1239-1244.

106 Joseph, J., Adler, J.R., Cox, R.S., Hancock, S.L. (1996). Linear accelerator-based stereotaxic radiosurgery for brain metastases: The influence of number of lesions on survival. Journal of Clinical Oncology, 14(4), 1085-1092.

105 Muacevic, A., Kreth, F.W., Horstmann, G.A., Schmid-Elsaesser, R., Wowra, B., Steiger, H.J., et al. (1999). Surgery and radiotherapy compared with gamma knife radiosurgery in the treatment of solitary cerebral metastases of small diameter. Journal of Neurosurgery, 91(1), 35-43.

104 Hakim, R.H., Alexander, E., Loeffler, J.S., Shrieve, D.C., Wen, P., Fallon, M.P., et al. (1998). Results of linear accelerator-based radiosurgery for intracranial meningiomas. Neurosurgery, 42(3), 446-453.

104 Heydarian, M., Hoban, P.W., Beddoe, A.H. (1996). A comparison of dosimetry techniques in stereotactic radiosurgery. Physics in Medicine and Biology, 41(1), 93-110.

103 Andrews, D.W., Suarez, O., Goldman, H.W., Downes, M.B., Bednarz, G., Corn, B.W., et al. (2001). Stereotactic radiosurgery and fractionated stereotactic radiotherapy for the treatment of acoustic schwannomas: Comparative observations of 125 patients treated at one institution. International Journal of Radiation Oncology Biology Physics, 50(5), 1265-1278.

103 Schneider, B.F., Eberhard, D.A., Steiner, L.E. (1997). Histopathology of arteriovenous malformations after gamma knife radiosurgery. Journal of Neurosurgery, 87(3), 352-357.

102 Young, R.F., Vermeulen, S.S., Grimm, P., Blasko, J., Posewitz, A. (1997). Gamma Knife radiosurgery for treatment of trigeminal neuralgia - idiopathic and tumor related. Neurology, 48(3), 608-614.

102 Kooy, H.M., Vanherk, M., Barnes, P.D., Alexander, E., Dunbar, S.F., Tarbell, N.J., et al. (1994). Image fusion for stereotaxic radiotherapy and radiosurgery treatment planning. International Journal of Radiation Oncology Biology Physics, 28(5), 1229-1234.

102 Coffey, R.J., Flickinger, J.C., Bissonette, D.J., Lunsford, L.D. (1991). Radiosurgery for solitary brain metastases using the Co-60 gamma unit - methods and results in 24 patients. International Journal of Radiation Oncology Biology Physics, 20(6), 1287-1295.

101 Kondziolka, D., Flickinger, J.C., Bissonette, D.J., Bozik, M., Lunsford, L.D. (1997). Survival benefit of stereotactic radiosurgery for patients with malignant glial neoplasms. Neurosurgery, 41(4), 776-783.

100 Flickinger, J.C., Lunsford, L.D., Coffey, R.J., Linskey, M.E., Bissonette, D.J., Maitz, A.H., et al. (1991). Radiosurgery of acoustic neurinomas. Cancer, 67(2), 345-353.

References

1 Ponce FA, Lozano AM: Highly cited works in neurosurgery. I. The 100 top-cited papers in neurosurgical journals. J Neurosurg 2010; 112:223-232.

-2 Ponce FA, Lozano AM: Highly cited works in neurosurgery. II. The citation classics. J Neurosurg 2010;112:233-246.

3 Ponce FA, Lozano AM: The most cited works in Parkinson's disease. Mov Disord (in press). 4 Garfield E: http://www.citationclassics.org. 